\title{
Biotecnologia e Alimentos Geneticamente Modificados:
}

\author{
Uma Revisão
}

\author{
Bruna Damaceno Vargas ${ }^{1}$, Arthur Basso², Thais Valença Rodrigues ${ }^{3}$, \\ Luana Bizzi Silva ${ }^{4}$, Monica Gatzke ${ }^{5}$, Matias Nunes Frizzo ${ }^{6}$
}

\begin{abstract}
RESUMO
A biotecnologia é uma associação de conhecimento científico e tecnológico que usa parte dele para produzir bens e serviços para a humanidade e ambiente, bem como a criação de seres vivos a partir de práticas laboratoriais. A biotecnologia é, hoje, necessariamente uma ferramenta a mais à disposição do pesquisador, que permite a aquisição de plantas geneticamente modificadas de maneira mais previsível com uma maior produção alimentícia. Dessa forma, o presente estudo apresentou como objetivo realizar uma pesquisa bibliográfica sobre a relação da biotecnologia e agricultura para a obtenção de alimentos geneticamente modificados. Para tal objetivo foi realizada uma revisão descritiva da literatura científica, abordando temas referentes à Biotecnologia, Agricultura e Organismos Geneticamente Modificados (OGMs). A ciência aplicada à agricultura tem conseguido não somente aumentar a produtividade dos alimentos, mas reduzir, ou mesmo eliminar, danos ao meio ambiente. Técnicas agrícolas modernas estão aumentando a produtividade e, ao mesmo tempo, melhorando a fertilidade do solo e protegendo o meio ambiente, ar, água e terra. Os OGMs são aqueles organismos, no caso as plantas, que têm seu material genético modificado pela introdução de um ou mais genes por meio da técnica de biologia molecular. Nesse contexto, é inegável a tendência de que a produção transgênica poderá gerar, além de um crescimento na produtividade agrícola, um aumento na ordem qualitativa dos alimentos, possibilitando uma ação na prevenção de inúmeras doenças.
\end{abstract}

Palavras-chave: Biotecnologia. Agricultura. Alimentos geneticamente modificados.

BIOTECHNOLOGY AND GENETICALLY MODIFIED FOODS: A REVIEW

\section{ABSTRACT}

Biotechnology is an association of scientific and technological knowledge that uses part of it to produce goods and services for humanity and the environment, as well as the creation of living beings from laboratory practices. Biotechnology today is necessarily a tool available to the researcher, which allows the acquisition of genetically modified plants in a more predictable way with a higher food production. Thus, the present study aimed to carry out a bibliographical research on the relationship between biotechnology and agriculture to obtain genetically modified foods (GMOs). For this purpose a descriptive review of the scientific literature was carried out, addressing subjects related to Biotechnology, Agriculture and Genetically Modified Organisms. Science applied to agriculture has succeeded not only in increasing food productivity, but in reducing or even eliminating environmental damage. Modern agricultural techniques are increasing productivity and at the same time improving soil fertility and protecting the environment, air, water and land. GMOs are those organisms, in this case plants, which have their genetic material modified by the introduction of one or more genes through the technique of molecular biology. In this context, it is undeniable the tendency that the transgenic production could generate, besides a growth in the agricultural productivity, an increase in the qualitative order of the food, enabling an action in the prevention of numerous diseases.

Keywords: Biotechnology. Agriculture. Genetically modified food.

Recebido em: $17 / 11 / 2015$

Aceito em: 30/10/2017

\footnotetext{
Aluna do curso de Graduação em Biomedicina CNEC-lesa. brunavargasvargas8@gmail.com

Aluno do curso de Graduação em Biomedicina CNEC-lesa. arthur_basso@hotmail.com

3 Aluno do curso de Graduação em Biomedicina CNEC-lesa. thaiis_vanessa@hotmail.com

${ }^{4}$ Aluno do curso de Graduação em Biomedicina CNEC-lesa. luanabizzisilva@ hotmail.com

5 Aluno do curso de Graduação em Biomedicina CNEC-lesa. monicagkelm@gmail.com

6 Professor do Departamento de Ciências da Vida - Unijuí. matias.frizzo@unijui.edu.br
} 


\section{INTRODUÇÃO}

O conceito de biotecnologia parte do uso de processos biológicos para a obtenção de bens, que vão de alimentos como, por exemplo, os que necessitam do processo de fermentação à produção de medicamentos em geral, utilizando células vivas e seus derivados sintéticos, como as enzimas e aminoácidos (GIEHL, 2006; VIEIRA, 2006).

A biotecnologia abrange processos muito variados desde a fermentação industrial, a terapia gênica e a clonagem. As repercussões médicas dos avanços na biotecnologia têm sido fascinantes, mas as implicações desses avanços para a saúde humana são nada menos do que impressionantes. O termo biotecnologia foi empregado originalmente pelo engenheiro húngaro Karl Ereky, em 1919, para se referir a "todas as linhas de trabalho, cujos produtos eram produzidos a partir de matéria bruta com auxílio de organismos vivos" (STEINBERG, 2002).

Atualmente, é uma área em franca expansão e tem muito a contribuir para a sociedade do futuro. As novas descobertas na área consistirão em um importante material para diversas aplicações. A biotecnologia pode ser uma solução de futuro para o problema da alimentação humana, por que graças a ela a produção anual dos alimentos pode aumentar consideravelmente para satisfazer às necessidades de uma população cada vez maior, e serão necessários produtos alimentícios econômicos e de melhor qualidade (ORGANIZAÇÃO..., 2008).

A manipulação genética dos alimentos pode ser a solução para evitar cenários de fome por todo o globo, posto que alimentos transgênicos podem ser mais nutritivos, mais resistentes a pragas e de maior adaptação em terrenos pobres em nutrientes do que os convencionais (THIEMAN; PALLADINO, 2004). Além disso, são de grande relevância por serem ricos em nutrientes e contêm mais minerais e vitaminas do que os encontrados em alimentos tradicionalmente cultivados. OGMs são conhecidos por ter características que atraem mais o consumo, inclusive um sabor mais agradável. Outra razão para os consumidores optarem por alimentos geneticamente modificados é que eles apresentam uma vida útil maior e, portanto, aumentando sua durabilidade para o consumo (BAWA, 2013).

Dessa forma, o presente estudo apresentou como objetivo realizar uma pesquisa bibliográfica sobre a relação da biotecnologia e a agricultura para obtenção de alimentos geneticamente modificados.

\section{Biotecnologia}

O termo "biotecnologia" está sendo usado desde a simbiose entre os avanços científicos, habilidades técnicas e sua aplicação para a modificação e geração de fenômenos vitais que acontecem, bem como a criação de seres vivos a partir de práticas laboratoriais (SCHRAMM, 2001). É uma associação de conhecimento científico e tecnológico que usa parte dele para produzir bens e serviços para a humanidade e ambiente, abordando um avanço progressivo graças à pesquisa que estuda o DNA desenvolvendo melhorias tecnológicas que estão diretamente associadas ao desenvolvimento da ciência (RENGIFO, 2009).

Esta ciência surgiu centrada na questão da saúde humana e animal, em que se utilizou microrganismos para a produção de antibióticos. Relatos de cultivos de células in vitro são datados da Segunda Guerra Mundial, quando a cultura de Penicillum notarum era aproveitada para a fabricação do antibiótico penicilina, cuja atuação como antibiótico foi desvendada por Alexander Fleming em 1929. Foi somente no fim do século 19 que ocorreu um acontecimento marcante para a biotecnologia atual. Em 1865, o monge Gregory Mendel conseguiu descobrir os segredos da hereditariedade, fazendo cruzamentos de ervilhas com distintas cores de flores no jardim de um monastério. Suas experiências criaram uma nova ciência: a genética. Atualmente, no entanto, não restam dúvidas de que a biotecnologia do século 21 é muito diferente daquela que havia no período de Mendel. Em 1953 ocorreu o descobrimento da hélice dupla do DNA (o material genético era duplicado e passado de geração a geração) por James Watson e Francis Crick. Este descobrimento acarretou consigo um novo conjunto de metáforas e uma nova língua para apresentar a ação biológica que transforma a forma pela qual os biólogos moleculares entendem as alterações genéticas em todos os organismos (CARRER; BARBOSA; RAMIRO, 2010).

O desenvolvimento acelerado do campo da biotecnologia aconteceu a partir da década de 70 , mais exatamente a partir de 1973, com o desenvolvimento da engenharia genética, informação que permite a alteração direta do material genético do DNA/RNA. Tal achado foi obra dos pesquisadores americanos Stanley Cohen e Herbert Boyer, que realizaram a alteração direta do material genético em que podem revolucionar o entendimento das áreas de diagnóstico, acompanhamento, tratamento, e também, para alguns tipos de organismos (vegetais), o melhoramento genético (GIEHL, 2006; VIEIRA, 2006). 
A biotecnologia moderna abrange a análise do ácido desoxirribonucleico (DNA), ácido ribonucleico (RNA), genômica, transcriptômica, proteômica, bioinformática e da engenharia genética aplicada à modificação genética de organismos vivos. A engenharia genética é a técnica de isolamento de DNA no laboratório, avaliando e inserindo-o em um organismo diferente, mas adequado à finalidade do procedimento da pesquisa. Esta biotecnologia moderna pode e deve exercer um papel extraordinário no desenvolvimento de novos produtos animais, vegetais, fungicos e bacterianos (ORTIZ, 2012).

\section{Biotecnologia na Agricultura}

A biotecnologia é, hoje, essencialmente uma ferramenta a mais à disposição do pesquisador, que permite a aquisição de plantas geneticamente modificadas de maneira mais previsível. Resumidamente, pode-se salientar que um gene, ao ser transferido para o genoma de outra espécie, vai determinar nessa espécie a mesma qualidade que determinava na espécie doadora. É por esse pretexto que o gene responsável pela produção de insulina humana, ao ser transferido para a bactéria Escherichia coli, torna essa bactéria produtora de insulina humana (BORÉM, 2005).

A ciência aplicada à agricultura tem conseguido não somente aumentar a produtividade dos alimentos, mas reduzir, ou mesmo eliminar, danos ao meio ambiente. Técnicas agrícolas modernas estão aumentando a produtividade e, ao mesmo tempo, melhorando a fertilidade do solo e protegendo o meio ambiente, ar, água e terra. Neste sentido, deve-se considerar, como já mencionado, que a atual geração está tomando o solo por empréstimo das gerações futuras, às quais ele deve ser devolvido com igual potencial produtivo e, se possível, melhorado. No melhoramento de plantas, considerado como ciência aplicada, é natural o emprego da nova tecnologia para a obtenção de outras variedades melhoradas (THIEMAN; PALLADINO, 2004).

Nesse contexto, a transgenia amplia consideravelmente a variabilidade disponível, pois pode utilizar a variabilidade existente em todos os seres vivos. Assim, quando uma característica desejável não é encontrada no genoma da espécie de interesse, mas o gene responsável por essa característica é identificado em outra espécie, tal gene pode ser transferido para a espécie a ser melhorada. Isso é possível porque o código genético é universal, ou seja, é o mesmo para todos os seres vivos (PATERNIANI, 2001).
$\mathrm{Na}$ agricultura, estudos envolvendo DNA das células ocorrem desde o início do século 20, como a cultura de tecidos, a fixação biológica de nitrogênio e o controle biológico de pragas. No conceito atual de biotecnologia, porém, incluem-se, também, técnicas modernas de modificação direta do DNA de uma planta ou de um organismo vivo qualquer, de forma a modificar-se exatamente as características desse organismo ou introduzir novas. O processo de transferência e modificação genética direta, conhecida como engenharia genética ou tecnologia do DNA recombinante, mais a genômica, ficaram conhecidas como "biotecnologia moderna", em contraposição à "biotecnologia tradicional ou clássica", que inclui as técnicas tradicionais que alteram seres vivos sem manipulação genética direta. Por conseguinte, o aparecimento da biotecnologia moderna marca o início de um novo aprendizado para a agricultura e conserva um papel de realce à genética molecular (JAMES, 2013).

Os progressos no campo da genética vegetal têm como resultado reduzir a dependência exagerada da agricultura das inovações mecânicas e químicas, que constituíram os pilares da revolução verde. Além do avanço da produtividade, a biotecnologia moderna pode contribuir para a diminuição dos custos de produção para a lavoura de alimentos com melhor qualidade e para o desenvolvimento de técnicas menos agressivas ao meio ambiente. Deste modo, a principal contribuição da biotecnologia moderna à agricultura é a probabilidade de criar novas espécies a partir da transferência de genes entre duas outras distintas. Essa transferência visa o incremento de uma planta com uma característica de interesse econômico, como é o evento das plantas resistentes a vírus ou a pragas (SILVEIRA; BORGES; BUAINAIN, 2005).

As plantas geneticamente modificadas têm demonstrado convincentemente benefícios extraordinários, como o aumento da produtividade e a diminuição do uso de pesticidas químicos, levando a um menor escoamento e menos envenenamentos. Um exemplo da importância na biotecnologia na agricultura é o o cultivo do algodão transgênico na China, que tem reduzido substancialmente a incidência de envenenamento por pesticidas entre os agricultores e suas famílias (BAWA, 2013).

Mediante a biotecnologia, a clonagem de genes em diversos tipos de organismos vegetais tem proporcionado uma menor necessidade de água, ou maior resistência à escassez de água, ou uso de organismos tolerantes a águas mais salinas, o que tem reforçado o uso desta tecnologia no mundo. Com secas recor- 
rentes sobre o Sul da Europa, Austrália, partes dos Estados Unidos e grande parte da África subsaariana, pequenas melhorias nas necessidades de água para a agricultura podem fazer uma grande diferença nos rendimentos e custo-efetividade da agricultura, sem contar na diminuição da pobreza e deficiências nutricionais nestas regiões (MILLER, 2010).

Além disso, são úteis no controle da ocorrência de certas doenças, pois, ao modificar o DNA de muitos alimentos, algumas das propriedades que provocam alergias são eliminadas com sucesso. Estes alimentos crescem mais rápido do que os alimentos que são cultivados tradicionalmente. Embora as sementes de tais produtos sejam bastante caras, o seu custo de produção é relatado como sendo menor do que a das culturas tradicionais em virtude da resistência natural para as pragas e insetos, reduzindo a utilização de pesticidas e inseticidas nocivos, tornando os alimentos livres de produtos químicos e favoráveis ao meio ambiente também (BAWA, 2013).

Nos últimos anos a produção de transgênicos se expandiu em praticamente todas as regiões agrícolas do planeta, e a adoção da biotecnologia na agricultura atinge níveis nunca alcançados por outras tecnologias avançadas em toda a história da agricultura (JAMES, 2013). Um estudo realizado em 2009 mostra que o Brasil passou a ser o segundo maior produtor de transgênicos do mundo pela primeira vez em 2009. O país supera a Argentina e fica atrás apenas dos EUA no ranking mundial de cultivos de OGMs, em um universo de 25 países produtores. 0 Brasil plantou 21,4 milhões de hectares com culturas geneticamente modificadas (GM) em 2009; um crescimento de $35,4 \%$ em relação a 2008 (equivalente a 5,6 milhões de hectares). De acordo com o Serviço Internacional para Aquisição de Aplicações em Agrobiotecnologia (ISAAA), trata-se do maior índice de crescimento entre os 25 países produtores de transgênicos, especialmente em razão da rápida adoção do milho e soja transgênicos (JAMES, 2013; VERCESI; RAVAGNANI; DI CIERO, 2009).

É marcante como a biotecnologia tem revolucionado a agricultura com modernas tecnologias que nos permitem identificar e escolher genes que codificam qualidades benéficas para serem usadas como marcadores moleculares nas técnicas de seleção assistida, ou ter a expressão de um determinado gene em outro organismo por transgenia e, assim, com maior precisão, obter novas características agronômicas e nutricionais desejáveis nos cultivos de plantas (CARRER; BARBOSA; RAMIRO, 2010).

\section{Organismos Geneticamente Modificados}

Entende-se por organismo geneticamente modificado (OGM) todo o organismo cujo seu material genético (DNA/RNA) foi manipulado de modo a favorecer alguma característica desejada, isto é, cujo material genético foi deliberadamente alterado pelo ser humano por meio de técnicas de biotecnologia. 0 primeiro organismo geneticamente modificado transgênico criado foi a bactéria Escherichia coli, que sofreu adição de genes humanos para a produção de insulina na década de 80 . Um transgênico é um organismo geneticamente modificado, mas este não é obrigatoriamente um transgênico; somente é considerado um transgênico se for introduzido no seu material genético parte de outro material genético de outra espécie (BECHANE, 2012).

Os termos transgênicos ou organismos geneticamente modificados (OGMs) referem-se a plantas, animais ou microrganismos que receberam genes de outros organismos no seu genoma para expressar características desejadas do organismo doador. Desta forma, a barreira do cruzamento entre espécies e até entre diferentes reinos foi rompida, trazendo inúmeras possibilidades para o melhoramento destes (VERCESIL; RAVAGNANI; DI CIERO, 2009; CORONA, 2007).

$O$ avanço da ciência nos últimos anos proporcionou a descoberta de novas tecnologias, um passo de essencial importância para o progresso da humanidade. No campo agroindustrial, os OGMs são considerados um avanço importante para a melhoria e para o aumento do processo produtivo. De fato, a criação das plantas geneticamente modificadas pode ser considerada um avanço científico e uma certeza de lucro para os grandes centros de biotecnologias e para os produtores rurais, uma vez que confere a elas, por meio da tecnologia do DNA recombinante, características que não seriam adquiridas por meio do melhoramento convencional. Os OGMs são aqueles organismos, no caso as plantas, que têm seu material genético modificado pela introdução de um ou mais genes mediante a técnica de biologia molecular. Assim, genes oriundos de diferentes vegetais, animais ou microrganismos podem ser introduzidos em um genoma vegetal receptor, conferindo às plantas novas características para a otimização da produção de alimentos, fármacos e outros produtos industriais (RIBEIRO; MARIN, 2012).

$A$ ascenção da engenharia genética e a introdução no mercado mundial de um novo tipo de alimento - "os geneticamente modificados ou transgênicos" - têm gerado muita polêmica. De um lado, a indústria da biotecnologia deposita extrema confiança na segu- 
rança da engenharia genética e sua importância para o desenvolvimento econômico e, de outro, há uma desconfiança generalizada da sociedade, motivada, em parte, pela ausência de informação. A falta de experiência com os OGMs e o potencial destes organismos para causar certos efeitos adversos como resultado dos genes inseridos em seus genomas, é à base das regulamentações de biossegurança. Apesar de que a capacidade de produzir alterações genéticas precisa aumentar a confiança de que as mudanças não intencionais no genoma não irão ocorrer, isto não assegura que todos os aspectos ecológicos importantes do fenótipo possam ser preditos (BOCCIA, 2015; ANEZ, 2006).

$\mathrm{Na}$ avaliação dos riscos associados com as novas técnicas de produção de alimentos, é necessário considerar também a maneira como essas técnicas diferem das tradicionais empregadas na agricultura. Quando são utilizados métodos tradicionais de melhoramento, visando a incrementar alguma característica em uma planta, por exemplo, os níveis de toxinas que ocorrem naturalmente podem ser aumentados como resultado do cruzamento feito. Desta forma, são necessários vários anos realizando-se outros cruzamentos para tentar livrar a nova planta da característica indesejável e, ao mesmo tempo, manter os benefícios do híbrido. De maneira semelhante, existem riscos associados aos altos níveis de produtos químicos utilizados atualmente, os quais permitem às culturas tolerarem insetos, doenças e condições climáticas adversas. Com o emprego das técnicas da biotecnologia, foram desenvolvidas novas variedades, muitas delas mais produtivas do que as tradicionalmente utilizadas e com uma necessidade muito menor de aplicação de agrotóxicos (XAVIER et al., 2008).

Os OGMs são cada vez mais utilizados em sistemas de investigação industriais para a produção de medicamentos de alto valor, combustíveis e produtos químicos. Isolamento genético e biotecnologia proporcionariam medidas essenciais de biossegurança para proteger partes vitais dos genomas, possibilitar OGMs seguros e auxiliar no desenvolvimento da biorremediação e probióticos (ROVNER et al., 2014).

Entre as características mais relevantes presentes em culturas geneticamente modificadas autorizadas, tolerância a herbicidas e resistência a insetos são prevalentes em todo o mundo. As características de valor agregado, no entanto, tais como diferente conteúdo de micronutrientes, amadurecimento mais rápido, melhor valor de avanço e altos níveis de antioxidantes, também ganharam muita atenção recentemente (GERDES et al., 2014; SIMÓ et al., 2014; RIBEIRO; MARIN, 2012).
Uma estratégia bem-sucedida deve combinar múltiplas abordagens que integram a melhoria convencional das culturas com a biotecnologia moderna, que mostrou resultados promissores otimizando a produtividade e contribuindo para a segurança alimentar e de fibra nos últimos dois anos (CHOUDHARY et al., 2014).

\section{METODOLOGIA}

O estudo foi desenvolvido mediante uma revisão descritiva da literatura científica, abordando temas referentes à Biotecnologia, Agricultura e Organismos Geneticamente Modificados. O processo de revisão foi realizado por uma busca na base de dados eletrônica, Pubmed e Scielo, a partir de artigos publicados no ano 2000, utilizando os descritores Biotecnologia (Biotechnology), Agricultura (Agriculture) e Organismos Geneticamente Modificados (Genetically Modified Food). Foi encontrado o total de 238 artigos. Estes passaram por uma análise de título e resumo para, então, refinar os artigos que estavam mais relacionados ao tema pesquisado "Biotecnologia e Alimentos Geneticamente Modificados" e que foram publicados a partir do ano 2000. Após essa análise foram selecionados 40 artigos, nos quais foi realizada uma leitura na íntegra, sendo selecionados 33 artigos. Os demais artigos (total de 211) foram excluídos por não abordarem a temática pretendida nesta revisão ou por terem sido publicados em anos anteriores a 2000, conforme mostra a Figura 1) a seguir.

Figura 1 - Fluxograma de análise dos artigos

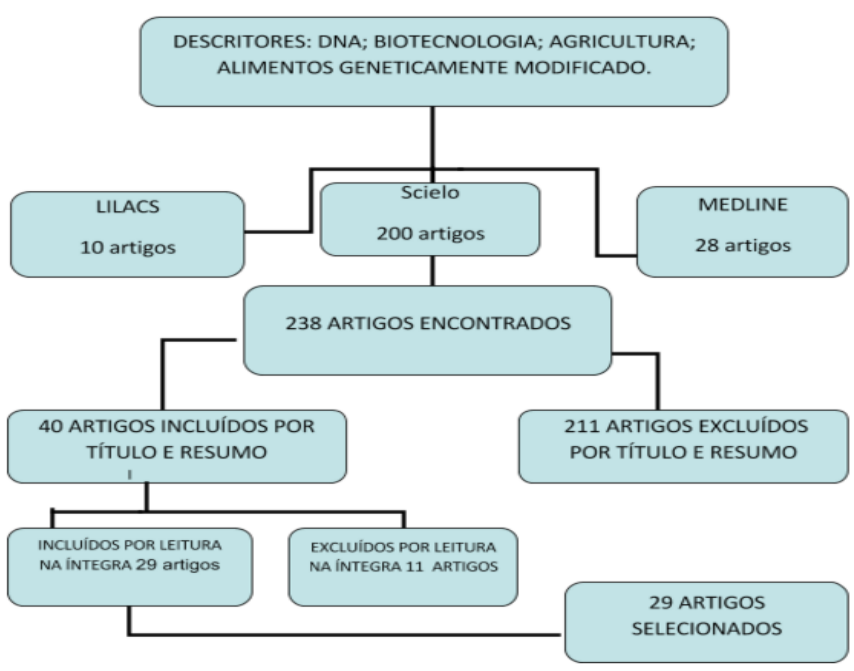

\section{RESULTADOS E DISCUSSÃO}

A ciência tem proporcionado uma ampla gama de possibilidades para modificar diferentes tipos de organismos, como também ganhos significativos de 
produtividade e rentabilidade da economia que envolve alimentos e demais produtos geneticamente modificados. Culturas transgênicas já são comercializadas há quase 20 anos, o que consiste num fato oportuno para discutir sobre as aplicações desta tecnologia, como os ganhos na produtividade, assim como no incremento de nutrientes e moléculas bioativas nos OGMs.

Um aspecto muito significativo associado à biotecnologia foi o desenvolvimento de tecnologias envolvendo melhoria nas metodologias e novas características expressas em variedades introduzidas na agricultura. Nesse ramo, em especial as indústrias, desenvolveram inúmeros transgenes formando verdadeiras bibliotecas de DNAs de transgenes associados as mais diversas funções, como resistência aos herbicidas, maior resistência à falta de água, assim como transgenes de proteínas ou elementos essenciais que enriquecem determinados alimentos ou são fonte de extração destas moléculas bioativas. Por outro lado, os OGMs expõem a saúde humana, o meio ambiente e a segurança alimentar a riscos, bem como proporcionam o aparecimento de "traços patógenos para humanos, animais e plantas; perturbações para o ecossistema; transferência de novos traços genéticos para outras espécies, com efeitos indesejáveis; dependência excessiva face às espécies, com ausência de variação genética" (COTA, 2015).

O avanço excessivo nessa tecnologia, no entanto, gerou uma grande variedade de espécies modificadas, mas que ainda necessitam de uma rigorosa avaliação pelos órgãos fiscalizadores, como o FDA, Ministério da Agricultura e Anvisa, para possibilitar uma segurança alimentar aos indivíduos, assim como possuir uma utilização segura ao meio ambiente enquanto produto cultivável.

No estudo de Rodríguez-Entrena et al. (2015) os resultados demonstraram a prevalência na preocupação com os fatores de risco ou desconfiança em relação aos OGMs. Além disso, a atitude inovadora quanto aos alimentos apresenta uma forte ligação com a falta de percepção da segurança destes. Para os autores, uma estratégia para melhorar a aceitação de alimentos GM é desenvolver uma estratégia transparente e equilibrada com informações acerca do risco potencial e informar sobre as avaliações para garantir segurança e qualidade a estes alimentos.

Watanabe e Nutti (2002) constatam que os alimentos geneticamente modificados constituem misturas complexas de vários compostos, e são caracterizados por uma ampla variação na composição e valor nutricional. Em virtude de seu volume e efeito de sa- ciedade, os alimentos são usualmente fornecidos a animais em quantidades equivalentes a um baixo número de múltiplos daquelas quantidades que provavelmente estariam presentes em uma dieta humana, o que implica baixos fatores de segurança. Há, ainda, que se considerar em maior profundidade o valor nutricional do alimento e, consequentemente, o balanceamento das dietas utilizadas. A detecção de quaisquer efeitos adversos potenciais e o relacionamento destes a uma característica individual do alimento, pode ser, entretanto, extremamente difícil. As análises para a determinação da composição de alimentos geneticamente modificados e seus derivados devem focar o conteúdo de nutrientes-chave (macro e micronutrientes), de componentes tóxicos-chaves e de fatores antinutricionais-chaves.

Não há como negar o aumento de produtividade agrícola associada aos transgênicos. Por outro lado, o uso em longo prazo desses alimentos poderá trazer algumas modificações ao meio, como a geração de novas pragas e plantas daninhas por intermédio de modificação das plantas que possuem substâncias nutritivas diferentes que levarão ao aparecimento de novos parasitas, danos a espécies não alvos com o transporte do pólen pelo vento, água, insetos e aves, e poderá ocorrer a contaminação de plantações nativas com os genes das modificadas, levando a uma propagação de genes para ouras plantas. Também pode ocorrer a alteração na dinâmica dos ecossistemas, a introdução de uma nova espécie em um meio e as monoculturas podem levar ao desaparecimento de outras espécies da cadeia alimentar que utilizavam o meio natural para a alimentação e reprodução. A produção de substâncias tóxicas, a degradação incompleta de produtos químicos perigosos codificados pelos genes modificados e a perda da biodiversidade, poderão levar ao desaparecimento de espécies mais frágeis em relação à adaptação ao meio ambiente mediante uma seleção "natural” (ALVES, 2004). Alguns componentes presentes em alimentos específicos podem se apresentar com efeitos biológicos potencialmente benéficos, como as isoflavonas da soja. Há a necessidade da verificação da ocorrência de quaisquer antinutrientes conhecidos, naturalmente presentes no alimento, para ter certeza de que os níveis dos mesmos não tenham aumentado significativamente como resultado da modificação genética em relação aos níveis encontrados em variedades convencionais (COSTA et al., 2011). Dessa forma, é necessário estimular a ampliação da atividade dos órgãos governamentais para avaliar os OGMs, a fim de responder essa demanda da população, com políticas de regulamentação para 
o uso destes alimentos assim como um rigoroso programa de controle sanitário objetivando torná-los confiáveis à população. Também tem-se direcionado a atenção para soluções em metodologias totalmente inovadoras que mantêm a perspectiva de uma utilização mais abrangente de modificação genética na agricultura como um todo, e, em especial, potencializar sua utilização na agricultura sustentável.

Assim como existem fatores a serem elucidados no emprego da biotecnologia na agricultura, são desenvolvidas ferramentas para o aumento da produtividade por meio dos mecanismos de recombinação gênica e das redes regulatórias envolvidas na tolerância a estresses ambientais (seca, frio, calor, salinidade e acidez do solo, solos menos férteis...), desenvolvimento e crescimento, "desenhando" novas plantas. As transformações genéticas de plantas cultivadas possibilitam validações funcionais de genes individuais selecionados, bem como a exploração direta dos transgênicos no melhoramento genético, visando à inserção de características agronômicas desejáveis (CARRER; BARBOSA; RAMIRO, 2010).

Graças à aplicação da biotecnologia no ramo agrícola, há uma previsão de crescimento do setor agrícola brasileiro, até o ano de 2019 , de $40 \%$, quando comparado ao ano 2000. Essa previsão de crescimento deve-se pelas condições econômicas e ambientais favoráveis do país e pela adoção massificada de culturas geradas com o auxílio da biotecnologia. Os produtos transgênicos estão sendo aplicados em praticamente todas as regiões agrícolas, e a biotecnologia é bastante utilizada pelos produtores, atingindo níveis nunca alcançados por outras tecnologias avançadas especialmente no âmbito agrícola (CARRER; BARBOSA; RAMIRO, 2010; JAMES, 2013).

Algumas questões, no entanto, necessitam de maiores esclarecimentos, pois ainda há, no Brasil, diversas polêmicas em torno dos transgênicos. De um lado há a defesa para a liberação dos transgênicos, pois são considerados eficientes em produtividade e frutos do avanço da ciência. Outros não concordam com a sua liberação imediata, pois pontuam a necessidade de mais estudos e pesquisas, apontando para os riscos de políticas liberalizantes deliberadas para estes produtos. $O$ foco principal não está relacionado à superprodução agrícola nem ao lucro das empresas e agricultores, tampouco à eficiência agronômica e econômica do cultivo, mas, sim, à saúde dos consumidores e preservação do meio ambiente. 0 principal argumento contrário a estes produtos é em relação aos riscos à saúde humana, animais e ao meio ambiente.
Dessa forma, volta-se à necessidade de maior empenho dos órgãos governamentais na fiscalização da padronização dos produtos aptos a serem cultivados.

\section{CONCLUSÃO}

Um dos maiores benefícios para a biotecnologia agrícola é a produção de plantas melhoradas geneticamente, estabelecendo suportes para as existências atuais e futuras de segurança alimentar, para a preservação dos recursos naturais e para o desenvolvimento de uma agricultura sustentável, assim como um significativo aumento na produtividade. Os OGMs são mais resistentes às pragas e à escassez de água, além disso, a nova geração de alimentos transgênicos com enriquecimentos nutricionais auxilia na prevenção de doenças crônicas não transmissíveis, como, por exemplo, na prevenção de doenças cardiovasculares. Nesse contexto, é inegável a tendência de que a produção transgênica poderá gerar, além de um crescimento na produtividade agrícola, um aumento na ordem qualitativa dos alimentos, possibilitando uma ação na prevenção de inúmeras doenças.

\section{REFERÊNCIAS}

ALVES, G. A Biotecnologia dos transgênicos: precaução é a palavra de ordem. Agrolink, v. 1, n. 1, p. 1-10, 2004.

ANEZ, T. Organismos geneticamente modificados: uma abordagem à luz do direito nacional e internacional. Revista da Faculdade de Direito, v. 18, n. 0, p. 1-12, 2006.

ARAUJO, J. Produtos Transgênicos na agricultura: questões técnicas, ideológicas e políticas. Caderno de Ciência e Teoria, v. 18, n. 1, p. 117-145, 2001.

BAWA, A. Segurança, riscos e preocupações comuns: alimentos geneticamente modificados. Journal of Food Science and Technology, v. 50, n. 6, p. 1.035-1.046, 2013.

BECHANE, V. Organismos geneticamente modificados. Jornada Científica, v. 1, 2012.

BOCCIA, F. Os alimentos geneticamente modificados e perspectiva do consumidor. Revista Nutricional Agricultura, São Paulo, v. 20, n. 1, p. 10-22, 2015.

BORÉM, A. A história da biotecnologia: a ciência que está surpreendendo até os mais otimistas. Biotecnologia Ciências \& Desenvolvimento, Viçosa, v. 10, n. 34, p. 10-12, 2005.

CARRER, H.; BARBOSA, A. L.; RAMIRO, D. A. Biotecnologia na agricultura. Estudos Avançados, v. 24, n. 70, p. 149-164, 2010.

CHOUDHARY, B. et al. Opções reguladoras para culturas geneticamente modificadas na Índia. Journal Plant Biotechnology, 12, n. 3, p. 135-146, 2014.

CORONA, S. Alguns conceitos relacionados com organismos geneticamente modificados (OGM). Revista Saúde Humana, v. 29, n. 1, p. 12-25, 2007. 
COSTA, T. E. M. M. et al. Avaliação de risco dos organismos geneticamente modificados. Ciência de Saúde Coletiva, Rio de Janeiro, v. 16, n. 1, p. 327-336, jan. 2011.

COTA, M. V. R. Os organismos geneticamente modificados e a rotulagem dos alimentos: uma análise a partir dos direitos dos consumidores. Curso de Direito, Lisboa, v. 6, n. 2, p. 1-25, dez. 2015.

GERDES, L. A abordagem estatística para quantificação de organismos geneticamente modificados (OGM), utilizando as distribuições de freqüência. Jornal BioMed Central, v. 1, n. 3, p. 567-587, 2014.

GERDES, M. J. et al. Emerging understanding of multiscale tumor heterogeneity. Front Oncol, v. 18, n. 4, 2014.

GIEHL, G. A biotecnologia e segurança dos alimentos transgênicos. Revista Âmbito Jurídico, v. 23, n. 5, p. 180-189, 2006.

ISAAC N.J.B. Statistics for citizen science: extracting signals of change from noisy ecological data. Britsh Ecological Society. Methods in Ecology and Evolution, v. 1, n. 5, p. 10521060, 2014.

JAMES, C. Status global das cultivares transgênicas comercializadas. Serviço Internacional para Aquisição de Aplicações em Agrobiotecnologia (ISAAA), 2013.

MILLER, H. A regulamentação da biotecnologia agrícola: a ciência mostra uma maneira melhor. N. Biotechnology, v. 23, n. 12, p. 324-336, 2010.

MOTTA, B. Responsabilidade por danos causados pela pesquisa e aplicação de organismos geneticamente modificados. Revisão Bibliográfica, v. 2, n. 1, p. 12-25, 2010.

ORGANIZAÇÃO MUNDIAL DA SAÚDE (OMS). Convenção sobre Diversidade Biológica, 2008.

ORTIZ, R. La adopción de la biotecnología moderna y su compatibilidad con una agricultura sustentable. Idesia, Arica, v. 30, n. 3, p. 3-10, 2012.

PATERNIANI, E. Agricultura sustentável nos trópicos. Estudos Avançados, São Paulo, v. 15, n. 43, p. 303-326, 2001.

RENGIFO, V. Modelo analógico para enseñar biotecnología: una experiência en el aula. Paradigma, v. 30, n. 2, p. 34-46, 2009.
RIBEIRO, I. G., MARIN, V. A. A falta de informação sobre os Organismos Geneticamente Modificados no Brasil. Ciênc. saúde coletiva, Rio de Janeiro, v. 17, n. 2, p. 359-368, 2012. RODRÍGUEZ-ENTRENA, M. et al. An assessment of the barriers to the consumers uptake of genetically modified foods: a neural network analysis. Journal Science of Food and Agriculture, n. 10, v. 2, p. 47-62, 2015.

ROVNER, A. J. et al. Recoded organisms engineered to depend on synthetic amino acids. Nature, v. 5, n. 518, p. 8993, 2015.

SCHRAMM, F. Bioética y biotecnología: lo humano entre dos paradigmas. Acta Bioethica, v. 7, n. 2, p. 15-27, 2001.

SILVEIRA, J.; BORGES, I. de C.; BOUAINAIN, A. M. Biotecnologia e agricultura da ciência e tecnologia aos impactos da inovação. São Paulo em Perspectiva, v. 19, n. 2, p. 101-114, 2005.

STEINBERG, F. Biotecnologia farmacêutica e bioterapia: uma visão geral. Society for Pharmaceutical Sciences, v. 12, n. 3, p. 1-17, 2002.

THIEMAN, W. J.; PALLADINO, M. A. Introduction to biotechnology. 4. ed. San Francisco: Pearson/Benjamin Cummings, 2004.

VERCESI, A. E.; RAVAGNANI, F. G.; DI CIERO, L. Uso de ingredientes provenientes de OGM em rações e seu impacto na produção de alimentos de origem animal para humanos. Revista Brasileira de Zootecnia, v. 38, n. 13, p. 56-68, 2009.

VIEIRA, A. Debates atuais sobre a segurança dos alimentos transgênicos e os direitos dos consumidores. Revista dos Tribunais, v. 23, n. 60, p. 37-57, 2006.

WATANABE, E.; NUTTI, M. R. Alimentos geneticamente modificados: avaliação de segurança e melhorias de qualidade em desenvolvimento. Revista Brasileira de Milho e Sorgo, Guaratiba, v. 1, n. 1, p. 1-14, 30 abr. 2002.

XAVIER et al. Genetically Modified Organisms. Revisão Bibliográfica, v. 12, n. 1, p. 24-37, 2008. 